\title{
The Perceptions of EFL Jordanian University Instructors of the Process of Teaching/Learning the Translation of Idioms
}

\author{
Amal Alrishan ${ }^{1}$ \\ ${ }^{1}$ Assistant Professor in TEFL, Department of English, AlBuraimi University College, AlBuraimi, Oman \\ Correspondence: Amal Alrishan, Department of English, AlBuraimi University College, Oman
}

Received: April 27, 2015

Accepted: May 11, 2015

Available online: October 26, 2015

doi:10.11114/ijsss.v3i6.1170

URL: http://dx.doi.org/10.11114/ijsss.v3i6.1170

\begin{abstract}
The study aimed at investigating the perceptions of EFL Jordanian University instructors of the process of teaching/learning the translation of idioms. The participants of the study were six M.A translation instructors at the University of Jordan and Yarmouk University who were selected purposefully. The total number of the instructors was 6. The instrument of the study was an interview with the translation instructors. The instructors indicated that teaching students how to translate idioms is not an easy task, especially when talking about opaque or peculiar idioms. Thus, some of them ask students to give the literal translation of the idiom if it conveys the meaning. Based on the findings of the current study, the researcher presented some recommendations and pedagogical implications.
\end{abstract}

Keywords: EFL translation instructors, perceptions, teaching idioms.

\section{Introduction}

It is noticed that idioms are used frequently in everyday situations and therefore need to be addressed by teachers. Therefore, idiom comprehension requires learners to go beyond a simple word-by-word comprehension strategy and to integrate figurative meaning. Idioms are very common in both written and spoken language.

Lundblom and Woods (2012, p.203) write that idioms "appear in conversation, print (magazines and newspapers), and media (movies, radio, and television)". Cooper (1998,p.255) claims that "when idioms occur on TV-shows, for example, in order to even understand the plot, the viewer often needs to be able to comprehend the idiom in question. Furthermore, idioms are the most frequently encountered in discourse".

Since idioms are part of the language system, students should learn them in order to be fluent in the target language. Burke (1998, p.1) claims that there is "absolutely no way a nonnative speaker of English could fully understand an American movie, TV show, news broadcast, or even a typical conversation without help because our language is loaded with nonstandard English, i.e., slang and idioms". He explains that if nonnative speakers do not understand idioms, they will never be able to completely integrate and, instead, they will always be outsiders.

Cooper (1998, p.259) believes that "sooner or later, imprecise idiomatic usage will cause difficulties even for a student with an excellent knowledge of grammar and a high level of vocabulary attainment". Thus, the fact that students most definitely will encounter idiomatic expressions on a daily basis (whether in a country where the native language is English, or just through TV shows and movies) is definitely a main reason as to why their idiom awareness needs to be developed during their language learning.

Cooper (1998, p 255) states that "idiom acquisition research has uncovered a number of findings that have pedagogical implication for idiom instruction". He mentions three competing hypotheses regarding how idioms are processed and these are developed into a systematic plan for teaching idioms in the classroom.

1. The literal first hypothesis which consists of two modes: one that processes the literal meaning and one that processes the figurative meaning of an idiom. The former is normally the active one while the latter comes into play when the literal meaning does not fit into the speech context.

2. The simultaneous processing hypothesis claims that idioms are stored and retrieved in the mental lexicon as chunks. Literal and figurative meaning interact and the interpretation that best fits the context is sorted out.

3. The direct access modelmakes use of the figurative meaning of an idiom. This proposes that a literal analysis of an 
idiomatic expression is very rare. Several articles (e.g. Boers, Piquer Píriz, Stengers and Eyckmans, 2009, Boers and Lindstromberg, 2005, Boers and Lindstromberg, 2006) have explored the possibility of using imagery and sounds to teach idioms. They discuss whether or not images or sounds can help learners to remember, and even re-produce, idioms.

Cooper further presents pedagogical implications for idiom instruction to native language learners, bilingual students and, foreign language learners. These are developed into teaching suggestions including concrete examples and a systematic plan. The author also presents us with a definition of idiom, statistics over Teaching Idiomatic Expressions.

Lundblom and Woods (2012) stress the importance of understanding idioms. They argue that they "are present in academic settings; therefore, the failure to comprehend idioms could impact academic performance, reading comprehension, written composition, and vocabulary, especially as the occurrence of idioms in classroom language increases as students advance in age and grade."

\subsection{Statement of the Problem}

The researcher has noticed that students encounter difficulties in translating idiomatic expressions. These difficulties usually result in poor translated texts. This could be due to the lack of translation strategies that help them to render the source expression in the target Language. This qualitative study is an attempt to approach the gap between the teachers' approaches in teaching idioms and their students' achievement in translating idioms. Few Jordanian studies shed light on the difficulties students encounter in translating idioms into Arabic. Among these are the studies conducted by Hussein, Khanji, and Makhzoumi (2000), Abu-Afeefa(1987), and Bataineh and Bataineh(2002) . The results of these studies indicated that Jordanian universities students encountered difficulties in translating idioms into Arabic, the negative transfer played a significant role in the translation of idioms, and that students have poor competence of different idioms. Since students of translation face difficulties in translating idioms, this study is an attempt to raise the teachers' awareness of these difficulties and try to explore the perceptions of teachers towards the process of teaching idioms.

\subsection{Purpose of the Study}

The present study investigates the perceptions of translation instructors in teaching the translation of idiomatic expressions into Arabic. It aimed at investigating the extent to which students are aware of the process of translation and of the strategies they are using. Students' failure to translate these idiomatic expressions will also indicate sources of difficulties that will be scrutinized. Finally, strategies used by translation instructors are examined as well. Based on the findings of the data analysis, pedagogical implications are presented concerning the teaching/ learning strategies and the translation strategies which instructors and students may utilize in the translation of the English idiomatic expressions.

\subsection{Question of the Study}

The study aims at answering the following question:

What are the translation instructors' perceptions of teaching the translation of English idioms into Arabic?

\subsubsection{Significance of the Study}

This study will provide students, instructors of translation, and courses writers with information on the perceptions of EFL translation instructors and the difficulties that students face in translating idioms. Instructors of translation may use these perceptions in the process of teaching idioms for translation students. They may give these perceptions, as well as the difficult idioms for students more attention in the teaching- learning process. The students' awareness of these perceptions will hopefully be raised when they are introduced with the strategies they utilize in translating idioms. As for the courses writers, it is hoped that more attention will be given to the idioms that are a source of difficulty for students such as opaque, unfamiliar, and peculiar idioms.

\subsubsection{Sites of the Study}

The study was carried out in these two universities:

1. University of Jordan (UJ) is a public university which was established in 1962 in Amman. In its Faculty of Foreign Languages, it offers 10 undergraduate programs. Among them are Bachelor's in the English Language and Literature, Bachelor's in Applied Linguistics and Master's in Translation (English-Arabic). Written Translation 1 (English -Arabic) course is taught at the BA level to the students of The English Language and Literature Department as an optional major requirement according to the 2009/2010 study plan and obligatory requirement to the students of double majors. 
2. Yarmouk University (YU) is a public university which was established in 1976 in Irbid. Among others, the Faculty of Arts has the Department of English Language and Literature, the Department of Foreign Languages, and the Department of Translation. The Department of Translation offers the General Translation 1 (English Arabic) course as an obligatory course to the first year students.

\subsection{Related Literature}

\subsubsection{Definitions of Idioms}

Baker (1992, p.63) tackles idioms and fixed expressions and defines idioms as "frozen patterns of language which allow little or no variation in form, and in the case of idioms, often carry meanings which cannot be deduced from their individual components". The speaker or writer, she adds, "cannot normally do any of the following with an idiom:

1. change the order of the words in it;

2. delete a word from it;

3. add a word to it;

4. replace a word with another;

Ghazala (2004, p. 21) defines idioms as "a fixed phrase whose form is unchangeable, and whose meaning is always the same, inflexible, metaphorical and indirect". Moon (2002, p.64) defines idioms as "items which are not the sum of their parts: They have holistic meanings which cannot be retrieved from the individual meanings of the component of words. Idioms are typically metaphorical in historical or etymological terms".

Cowie and Mackin (1975, p.viii) also discuss the multi-word nature and semantic opacity of the idiom: an idiom, they write, "is a combination of two or more words which function as a unit of meaning". Cowie and Mackin (1975) and Cowie (1998) describe idiomaticity as "a feature cutting across all fixed expressions rather than have idioms as a separate category included within and subsumed by an overall framework of fixed expressions". An idiom, according to Richards and Schmidt (1990, p. 246), can be defined as: "an expression which functions as a single unit and whose meaning cannot be worked out from its separate parts". For example, the meaning of the idiom to have a bee in one's bonnet is: "to be continually occupied with, or obsessed by one idea or thing."

\subsubsection{Classification of idioms}

Moon (1998, p.4) claims that an idiom denotes a general term for many kinds of multi-word expressions 'whether semantically opaque or not'. To understand it better it is necessary to look at the typology that is proposed by Fernando (1996, p.35), who distinguishes three sub-classes of idioms:

1. Pure Idioms: Fernando defines pure idiom as 'a type of conventionalized, non literal multiword expression' (p.36). Pure idioms are always non literal. However, they may be either invariable or may have little variation. In addition, idioms are said to be opaque, For example, pure idiom to spill the beans has nothing to do with the beans.

2. Semi-idioms: Semi-idioms are said to have one or more literal constituents and one with non literal sub sense. Therefore, this type of idioms is considered partially opaque. For example, foot the bill which means 'pay' is semi-idiom.

3. Literal idioms: This sub-class of idioms are either invariable or allow little variation. In addition, literal idioms are considered to be transparent as they can be interpreted on the basis of their parts. For example, of course, in any case, for certain.

Chen and Lai (2013, p.13) write that traditional methods and approaches, involving, for example, rote learning and memorization, can be "time- and effort-consuming". They added that "idioms should be learned through the process of raising L2 learners' awareness of conceptual metaphors behind these expressions". They also claim though that this process "fails to notice culture entailments embedded in conceptual metaphors". Elements such as cultural background, living environment and cross-cultural differences will affect learners' ability to understand idioms.

Boers (2008, p.14-16) believes that when teaching idioms through memorization, reference books are often used. These books can be useful to find an idiom's translation quickly. However, reference books are lacking because they do not provide any background information or explanation for the idioms. Additionally, "this type of rote learning that may result in short retention of what they have learned is impractical". To teach idioms through awareness-raising activities, though, by "seeking logical arrangements of idioms and putting them in a more meaningful learning context for L2 learners and comparing the learners' L1 and L2 can help them to observe the differences between the languages and, thus, be able to discuss the L2 idioms' possible origins and remember them through imagery. Unfortunately, this does not work with all idioms and "may be particularly difficult for L2 learners who do not share a similar cultural and historical background with native speakers of English". 
Chen and Lai continue to assert that another type of activity involves teaching idioms as metaphors through conceptual metaphors. "Researchers have systemized idioms based on their common concepts" and "the idioms are motivated conceptually by general knowledge of the world". For example, a connection between fire and anger in idioms can be found. This has been useful for improving "meaning comprehension" and "extends retention of the expressions learned". Nevertheless, it is not always easy to find the patterns and connections between the idiomatic expressions. If learners fail to do this, they will misunderstand the idiom in question. Also, it is more difficult for EFL learners to comprehend "metaphor-based expressions whose conceptual metaphors were distinct from their native language" (Ibid, p. 16).

Cooper (1998) presents concrete teaching and learning suggestions that relate to Gardner's theory of multiple intelligences. These are summarized by the following:

1- Choosing Idioms - It is important to find those that are frequently encountered in everyday situations that are not grammatically complex and have transparent figurative meanings. As suggested above, L2-learners benefit from starting with idioms identical in both languages before moving on to those that require more practice and explanation.

2- Discussing Idioms - Learners often lack the knowledge to comprehend an idiom, simply because they do not know what figurative language is. "The teacher can lead a discussion about metaphors, similes, and idioms and the purpose they fulfill in speech and writing" (Ibid., p. 262).

3- Defining Idioms - After the initial discussion, the teacher should "present the new idiom within the larger context of a short paragraph or a dialogue" (Ibid., p. 262). If the information about how the figurative meaning originated is available this can be used to contrast the literal and figurative meaning. The degree of formality should also be explained before letting students practice idioms in different constructed situations.

4- Dividing Idioms into Categories - "Dividing idioms into thematic categories will make them easier to learn, for the student can study them as groups composed of elements that have common features rather than as lists of unrelated expressions to be memorized" (Ibid., p. 263).

5- Drawing Idioms - The relationship between the literal and figurative meaning of an idiom can be illustrated by using pictures. The class could create a dictionary of idiomatic sayings, which then can be illustrated or developed by interviewing relatives about their favorite idioms.

6- Dramatizing Idioms - Since misinterpretations of idioms can easily lead to humorous situations, these can be acted out. By creating skits or playing charades the class can create a game where the literal meaning is acted out and the figurative has to be guessed.

7- Retelling Exercise - The students retell a story made up by the teacher, using asusing as many idioms as possible.

8- Add-on Story - The teacher starts the narrative by using one of the idioms written on the board, after which each student adds a sentence including one of the idioms.

9- Discuss Idioms from Newspaper Comic Strips - Each student selects a comic strip containing an idiomatic expression. These are then written down on the board and discussed.

10- Idioms in Cartoons - The teacher collects samples where the literal meaning and the figurative meaning are used to achieve humorous situations and discusses it with the students.

11- Idioms from TV Shows - "Running lists of idioms can be compiled from TV shows" (Ibid., p. 264), shows can be shown in class and the idioms discussed.

12- Paragraph Completion - Students complete a paragraph or dialogue with the appropriate idiom and can be shown that they were able to use the correct one because of the context provided.

13- Interview Classmates - By interviewing native speakers learners can be taught the meaning and appropriateness of certain idioms in specific situations. Idiom-of-the-Day Mobile - Mobiles created by the students with idioms can be hung from the ceiling.

In summary, Cooper (1998) proposes that students benefit from activities that appeal to their various intelligences such as linguistic, musical and intrapersonal intelligence.

In addition, Bromely (1984) presents several useful pedagogical ideas to teach idioms effectively. She identifies three major components (definition, usage and application) that have to be taken into consideration when teaching.

Definition - When an idiom is encountered in a context (either speech or writing), they can be discussed immediately by comparing the literal and actual meaning. A useful tool is to find out where the idiomatic expression has its origin, providing the learners with a context and concept. 
However, idioms can also be taught directly by activities such as an "Idiom a Day" or an "Idiom of the Week" that increase students' awareness. Another idea is to create lists that classify idioms involving colors, animals etc.

Usage - After the first stage, the students should be given as many opportunities as possible to use the idioms in class. This can be done by using both oral and written exercises where the students "identify its equivalent from a number of alternatives" (Ibid., p. 274) or "rewriting sentences to include an appropriate idiom" (Ibid., p. 275).

Dramatizations -such as charades can be used to create games where the students act out the literal interpretations while trying to identify the actual or original meaning.

Illustrations with matching definitions of idioms can be done individually or in pairs to create a class dictionary of idiomatic sayings.

Suggestions for oral exercises include giving the students the responsibility of using an idiom once a day for a week or the teacher might use the same idiom once a day for a week asking the students to spot it.

Application - "Understanding idioms used in class need to be accompanied by opportunities to apply this new knowledge outside the school" (Ibid., p. 275). This can be done by creating lists of idioms heard on the radio, TV or in books. They can also be used for creative writing such as making up the origin and then comparing it to the actual one.

In the same stream, teaching translation strategies has become a relevant part of university translation courses. Strategies, such as those outlined by Baker (1992) including translation by a more general word, translation by a less expressive word, translation by cultural substitution, and paraphrasing are useful in different ways. First, they help solve equivalence problems; second, they favor translation-as-a-process awareness and, third, they present students with opportunities to discuss and reflect on contextualized theoretical issues. Finding equivalences to convey the same meaning of a source language text in a target language is not always an easy task. The difficulties associated with the process of translation have been widely commented on by scholars and professional translators, but they become highly remarkable when we deal with language students learning to translate into their native language. To overcome the difficulties arising from translating texts, students should be introduced to the theory of translation, and should be trained in the various strategies to solve translating problems and the lack of translation equivalences among languages.

Newmark (1981, p.20) maintains that "students should be aware that their work as translators is developed in four levels : translation as a science", which entails the knowledge and verification of the facts and the language that describes them; "translation as a skill", which calls for appropriate language and acceptable usage;" translation as an art", which distinguishes good from undistinguished writing and is the creative, the intuitive, sometimes the inspired, level of the translation; and finally, "translation as a matter of taste", where argument ceases, preferences are expressed, and the variety of meritorious translations is the reflection of individual differences.

To sum up, the involvement of learners in the teaching-learning process of translation and their knowledge of the translation strategies play a vital role in enhancing the process of learning and the use of translation strategies in the process of translation, a matter which is emphasized by many theorists. The student's role is enhanced by adopting the strategic learning approach which is represented for the purpose of this research by the employment of specific strategies for translating certain idiomatic expressions from English into Arabic.

\subsection{Related Studies}

Boers, Lindstromberg, Littlemore, Stengers and Eyckmans (2007) examined how source domain of idioms motivated their figurative meanings with regard to cross-cultural variations. The logic of their study was the assumptions that source domain of many idioms were cultural dependent. So, cross- cultural variations would be a significant variable in the comprehension of idiomatic expressions as it seemed to influence the opacity of idioms. The study was accomplished through an idiom teacher exercise (A self - study technique consisting of 1200 on-line exercises on 400 idioms). The exercises included matching to source task for the experimental group and matching to definition task for the control group followed by a gap filling task for both groups as a post test. This experiment was performed in two phases; the first one in a context of learner autonomy and the second one in a context of explicit guidance by the teacher. Results revealed that etymological elaboration could help learners effectively comprehend and recall figurative idioms. In the learner autonomy context, etymological elaboration seemed to be more effective to only transparent idioms with familiar source domain while with explicit teacher guidance; the technique was beneficial for even opaque idioms.

Parallel to their previous study,Boers, Lindstromberg, Littlemore, Stengers and Eyckmans (2008) conducted another study with Chinese and Iranian EFL learners on the effectiveness of etymological elaboration.( Boers, et.al 2008) suggested that creating a connection between figurative idioms and their literal origins can indeed be a pedagogically effective technique to help learners to remember the given expressions. One way to help learners create such connection is the use of images. In their study, they compared a group of students exposed to online exercises in which the explanation about the origin of the idioms was accompanied by a picture with another group who was presented with no 
pictures to elucidate the verbal input. The performance under picture enhanced version revealed a significant improvement of the meaning of multiple choice exercises (Boers, Piquer Píriz, Stengers \& Eyckmans, 2009) investigated whether cognitive-style or learning-style variables have an impact on the relative effectiveness of pictorial elucidation as a mnemonic aid? More specifically, do high imagers and low imagers respond differently to this kind of Teaching Idiomatic Expressions stimulus? The study conducted for this article had 38 participants between 19 and 21 years old. Their proficiency levels in English were varying. 100 frequently used idioms were introduced. Multiple-choice tests in meaning and origin, and a gap-fill exercise were created and used. The results of the gap-fill tests, with pictures or just verbal explanation, were similar. Consequently, "the addition of pictures had little impact on students' recollection of the lexical make-up of idioms.

Zhang (2009) designed a web-based learning experiment with Chinese students in order to estimate the actual effect of etymology on receptive and productive knowledge of target idioms in an on-line environment. The participants were given non- line learning units that were designed in different forms for two groups. In the learning unit of the experimental group, each idiom was associated with information about their origin, but the control group lacked such information, and received only brief explanations about figurative meanings of idioms. The results of the study showed that while etymological information did not have more influence on L2 idiom acquisition than traditional rote learning, it was effective on the retention and productive knowledge of target idioms.

Bagheri and Fazel (2010) explored the role of the etymological elaboration in Iranian learners' comprehension and retention of idioms on the basis of dual coding theory. The same treatment as Boers et el's work (2007) was given to 50 advanced EFL learners in experimental and control groups. The results of this study were in line with the previous studies and confirmed that etymological elaboration enhanced idiom le Pimenova (2011) examined idiom comprehension strategies of EFL learners in India with dissimilar first language (L1) and challenges that English and Russian learners faced during a Think-Aloud reading task. The results showed that learners could transfer their L1 strategies to L2, FL students do not always know whether L1 strategies will be effective while reading a FL text.

Tran (2012) investigated the situation of teaching and learning idioms at a university level in Vietnam in a foreign language context. He examined the evaluation of the idiom teaching process in three language classes over a15-week period for pre-service teachers of English. The data were collected though questionnaires, in-depth interviews and email guided reflective writing. The analysis revealed that EFL teachers and students at the university achieved moderate effectiveness in idiom learning. Both teachers and students believed that students are motivated, felt relaxed and confident and actively participated in idioms learning activities in this foreign language context. The findings also revealed that students demonstrated the process in idiom comprehension as well as in idiom production though the evidences in the comprehension of idiomatic phrases are more evitable. The results indicated significant effects of the context in idiom learning when idioms were creatively used in integrated skill tasks. The findings also implied that idiom learning should receive more attention in EFL learning context.

Chen and Lai (2013) conducted a case study in an EFL writing class to investigate the effect of the methods used in teaching idioms. Essays written by the students before and after their instruction were 19 university students participated in the case study. They were Chinese native speakers who had learned English for at least seven years e analyzed. They were. After learning about, understanding and creating metaphoric mappings, the students edited their first draft of the essay and added as many idioms to it as they could. A week later, they turned in their essays to the instructor who analyzed and investigated how the students used idiomatic expressions as well as to measure the effects of the new cognitive-oriented teaching method.

Results showed that the students increased frequencies of using not only common idiomatic expressions but also creative analogies comprising vivid images based on the conceptual metaphors taught. Additionally, they used L2 expressions whose conceptual metaphors also existed in L1 more often, then expressions whose conceptual metaphors were exclusive in L2. Such findings affirm the importance of culture and provide valuable insight to EFL teachers in adopting cognitive-oriented method to teach English idioms.

After reviewing the related literature, the researcher noticed that EFL students encounter difficulties in rendering idioms from English into Arabic. These difficulties arise from the fact that idioms are culture-bound expressions which cannot be translated literally. Furthermore, the previous literature indicates the lack of awareness on the part of students of the strategies to use in translating idiomatic expressions. There is a tendency for translation students to follow the syntactic and lexical structure of the source text too closely, and this often leads to translations that sound non-idiomatic. Besides, the previous studies emphasized the importance of students' awareness and knowledge of translation strategies as well as the role of instructors in improving students' ability in using the translation strategies in the process of translation. Thus, this study attempts to investigate the strategies used by EFL students in translating idioms which are culture-bound expressions, as well as the strategies used by translation instructors in teaching these strategies. It is 
hoped that the findings will provide the translators, students, and instructors with information on such strategies and the difficulties students face when translating these idioms. Instructors of translation may use these strategies and the students' awareness of these strategies will hopefully be raised. This study is different from the previous studies in the following aspects:

1. It encompasses the notion of utilizing students' strategies in teaching and learning translation in light of Baker's Taxonomy of translation strategies that the researcher tackled in Chapter Two of this study.

2. Students' perceptions in addition to instructors' practices and perceptions with regard to learning and teaching idioms are also investigated.

3. The current study adopts authentic texts that would hopefully be similar to the English texts that EFL majors would normally read outside the classroom, for example, the text they would read for pleasure.

4. The current study is intended to provide insights into how EFL students, in particular, translate idioms while reading authentic texts, unlike many previous studies that presented idioms in isolation or in contrived texts.

5. Many of the previous studies investigated L2 and EFL learners' techniques of idioms' comprehension and subjects' guessing techniques in general, while this study investigates the strategies utilized by EFL translation students in particular and the difficulties they encounter in translating idioms.

\section{Method}

\subsection{Design and Variables of the Study}

The current study is a qualitative one. It analyses the interviews 'responses.

\subsubsection{Participants of the Study}

The participants of the study were selected purposefully. They were all M.A translation instructors at the university of Jordan and Yarmouk University. The total number of the translation instructors is 6.Table 1 presents the translation instructors' bio data.

Table 1. Translation Instructors' Characteristics

\begin{tabular}{|c|c|c|c|c|}
\hline University & Qualification & & Teaching experience & Department \\
\hline University of Jordan & $\begin{array}{l}1 \\
\text { Translation }\end{array}$ & Ph.D in & 20 years & $\begin{array}{l}\text { English Language and } \\
\text { Literature }\end{array}$ \\
\hline & $\begin{array}{l}2 \\
\text { Linguistics }\end{array}$ & ph.D in & 15 years & \\
\hline Yarmouk University & $\begin{array}{l}1 \\
\text { Translation } \\
2 \\
\text { Linguistics } \\
3 \\
\text { linguistics } \\
4 \\
\text { Linguistics }\end{array}$ & $\begin{array}{l}\text { Ph.D in } \\
\text { Ph.D in } \\
\text { Ph.Din } \\
\text { Ph.D in }\end{array}$ & $\begin{array}{l}20 \text { years } \\
5 \text { years } \\
10 \text { years } \\
10 \text { years }\end{array}$ & Translation \\
\hline
\end{tabular}

Table 1 shows that all the translation instructors at both universities hold Ph.D in Translation or Linguistics with practical experience that ranges from 5 to 20 years. Instructors at both universities teach translation courses to M.A students at the Department of English Language and Literature and the Department of Translation.

\subsection{Research Instrument}

\subsubsection{Interview with the Instructors}

In order to obtain the perceptions of the translation instructors concerning the process of teaching the translation of English/ Arabic idioms, the researchers conducted an interview with them. The interview included questions on how to teach idioms. The interviews were recorded, transcribed, and analyzed.

The researchers, then content analyzed the interviews. The content analysis included categories and subcategories in light of the questions of the interview and their answers. The main categories of analysis were: general pedagogy of idioms which included: prerequisite cultural courses, problematic idioms to students, strategies of translating idioms, and feedback of translating idioms. While specific pedagogy of idioms included: strategies of teaching the translation of idioms.

\subsection{Reliability of the Instructors' Interview Analysis}

To find out the intrarator reliability coefficient of the content analysis, the researchers analyzed three interviews twice with one month between the first and the second analysis. As for the inter-reliability coefficient, the researchers asked 
a colleague to analyze three instructors' interviews transcriptions. Table 5 presents the results of the two analyses.

Table 2. Inter-rator and Intra-rator Pearson Correlation of the Instructors' Interviews

\begin{tabular}{l|l|l}
\hline Categories of Analysis & Agreement Percentages \\
\cline { 2 - 3 } & Inter-rater & Intra-rator \\
\hline General Pedagogy of Idioms & 90.29 & 90.29 \\
\hline Specific Pedagogy of Idioms & 92.75 & 92.75 \\
\hline Over all & 92.24 & 93.25 \\
\hline
\end{tabular}

Table 2 shows that the inter-rator reliability coefficient of the content analysis of the instructors' interview is 92.75 and for the intrarator coefficient the agreement percentage is 93.30 which indicates a high consistency between the two analyses.

\subsection{Data Analysis}

2.4.1 Analyzing the results of the instructors' interviews

Content analysis methodology was used to analyze the interviews. The researcher content analyzed the interviews. The content analysis included categories and subcategories in light of the interviews questions and answers. The ideas under each category were classified into degrees: high, moderate, and low. As for the high ones, the idea range is higher than $66.66 \%$. The range for the moderate is $33.34 \%-66.66 \%$, and the low ideas range is lower than $33.34 \%$.

\section{Results}

The question asks about the translation instructors' perceptions of their teaching of how to translate English idioms into Arabic. To answer the question, a content analysis of the interviews with the instructors was carried out. Frequencies and percentages per each idea were calculated. The results are presented in a descending order in Table 3.

Table 3. Frequencies and Percentages of the Instructors' Perceptions in a Descending Order

\begin{tabular}{|c|c|c|c|c|c|c|c|}
\hline $\begin{array}{l}\text { Categories } \\
\text { of Analysis }\end{array}$ & Subcategorie & of Analysis & Rank & ID & Idea & \# & $\%$ \\
\hline \multirow{20}{*}{$\begin{array}{l}\text { General } \\
\text { pedagogy of } \\
\text { idioms }\end{array}$} & \multirow{10}{*}{$\begin{array}{l}\text { Teaching } \\
\text { idioms } \\
\text { in } \\
\text { translation }\end{array}$} & \multirow{2}{*}{$\begin{array}{l}\text { How do you } \\
\text { teach idioms }\end{array}$} & 1 & 1 & Through oral or written contexts & 3 & $50.00 \%$ \\
\hline & & & 2 & 2 & $\begin{array}{l}\text { In normal language and not } \\
\text { idiomatically }\end{array}$ & 1 & $16.67 \%$ \\
\hline & & \multirow{5}{*}{$\begin{array}{l}\text { How do you } \\
\text { teach the } \\
\text { process of } \\
\text { translating } \\
\text { idioms to } \\
\text { students? }\end{array}$} & 1 & 1 & $\begin{array}{l}\text { By asking students to translate } \\
\text { them } \\
\text { Interpretation }\end{array}$ & $\begin{array}{l}3 \\
3\end{array}$ & $\begin{array}{l}50.00 \% \\
50.00 \%\end{array}$ \\
\hline & & & 3 & 3 & By differentiating between literal & & \\
\hline & & & & & and idiomatic meaning & 2 & $33.33 \%$ \\
\hline & & & 4 & 5 & $\begin{array}{l}\text { By tackling the issue of } \\
\text { equivalence }\end{array}$ & 2 & $33.33 \%$ \\
\hline & & & 5 & 2 & $\begin{array}{l}\text { Providing idioms in advance and } \\
\text { asking for their meaning using } \\
\text { references }\end{array}$ & 1 & $16.67 \%$ \\
\hline & & \multirow{3}{*}{$\begin{array}{l}\text { When to } \\
\text { teach idioms }\end{array}$} & 1 & 2 & When coming up with idioms & 6 & $100.00 \%$ \\
\hline & & & 2 & 1 & Incidentally & 5 & $83.33 \%$ \\
\hline & & & 3 & 3 & $\begin{array}{l}\text { When we tackle cultural } \\
\text { expressions }\end{array}$ & 3 & $50.00 \%$ \\
\hline & \multirow{6}{*}{$\begin{array}{l}\text { Problematic } \\
\text { idioms } \quad \text { to } \\
\text { students }\end{array}$} & \multirow{6}{*}{$\begin{array}{l}\text { What are the } \\
\text { idiomatic } \\
\text { expressions } \\
\text { that are a } \\
\text { source of } \\
\text { difficulty for } \\
\text { students }\end{array}$} & 1 & 5 & Unfamiliar idioms & 6 & $100.00 \%$ \\
\hline & & & 2 & 2 & Culture bound idioms & 5 & $83.33 \%$ \\
\hline & & & 3 & 3 & Opaque idioms & 5 & $83.33 \%$ \\
\hline & & & 4 & 6 & Idioms with different images & 4 & $66.67 \%$ \\
\hline & & & 5 & 1 & Peculiar idioms & 3 & $50.00 \%$ \\
\hline & & & 6 & 4 & Lengthy idioms & 2 & $33.33 \%$ \\
\hline & \multirow{4}{*}{$\begin{array}{l}\text { Prerequisite } \\
\text { courses }\end{array}$} & \multirow{4}{*}{$\begin{array}{l}\text { Students } \\
\text { need to take } \\
\text { cultural } \\
\text { specific }\end{array}$} & 1 & 1 & Supportive & 3 & $50.00 \%$ \\
\hline & & & 2 & 3 & English only & 3 & $50.00 \%$ \\
\hline & & & 3 & 5 & English and Arabic & 3 & $50.00 \%$ \\
\hline & & & 4 & 2 & Unsupportive & 1 & $16.67 \%$ \\
\hline
\end{tabular}




\begin{tabular}{|c|c|c|c|c|c|c|c|}
\hline $\begin{array}{l}\text { Categories } \\
\text { of Analysis } \\
\end{array}$ & \multicolumn{2}{|c|}{ Subcategories of Analysis } & \multirow{2}{*}{$\begin{array}{l}\text { Rank } \\
5 \\
\end{array}$} & \multirow{2}{*}{$\begin{array}{l}\text { ID } \\
4 \\
\end{array}$} & Idea & \multirow{2}{*}{$\frac{\#}{0}$} & \multirow{2}{*}{$\%$} \\
\hline & & courses & & & Arabic only & & \\
\hline & \multirow{10}{*}{$\begin{array}{l}\text { Elaboration } \\
\text { in explaining } \\
\text { the } \\
\text { differences } \\
\text { between } \\
\text { E and } \\
\text { Arabic }\end{array}$} & \multirow{5}{*}{$\begin{array}{l}\text { Instructors } \\
\text { elaborate in } \\
\text { explaining } \\
\text { the } \\
\text { differences } \\
\text { between } \\
\text { English and } \\
\text { Arabic } \\
\end{array}$} & 1 & 4 & $\begin{array}{l}\text { If students lack cultural } \\
\text { information }\end{array}$ & 5 & $83.33 \%$ \\
\hline & & & 2 & 2 & Depending on students level & 4 & $66.67 \%$ \\
\hline & & & 3 & 3 & Depending on students motivation & 4 & $66.67 \%$ \\
\hline & & & 4 & 5 & In case of difficult idioms & 3 & $50.00 \%$ \\
\hline & & & 5 & 1 & To a large extent & 0 & $0.00 \%$ \\
\hline & & \multirow{5}{*}{$\begin{array}{l}\text { Instructors } \\
\text { give } \\
\text { examples } \\
\text { from both } \\
\text { languages }\end{array}$} & 1 & 2 & Always & 5 & $83.33 \%$ \\
\hline & & & 2 & 4 & When needed & 5 & $83.33 \%$ \\
\hline & & & 3 & 3 & To clarify the meaning & 4 & $66.67 \%$ \\
\hline & & & 4 & 1 & When committing a big mistake & 2 & $33.33 \%$ \\
\hline & & & 5 & 5 & Extensively & 2 & $33.33 \%$ \\
\hline & \multirow{4}{*}{$\begin{array}{l}\text { Feedback in } \\
\text { translating } \\
\text { idioms }\end{array}$} & \multirow{2}{*}{$\begin{array}{l}\text { Formative } \\
\text { assessment }\end{array}$} & 1 & 1 & Quizzes and exams & 2 & $33.33 \%$ \\
\hline & & & 2 & 2 & Class discussion & 2 & $33.33 \%$ \\
\hline & & \multirow{2}{*}{$\begin{array}{l}\text { Teachers } \\
\text { Advice } \\
\text { students }\end{array}$} & 1 & 2 & $\begin{array}{l}\text { Consulting English dictionaries of } \\
\text { idioms }\end{array}$ & 4 & $66.67 \%$ \\
\hline & & & 2 & 1 & Reading about the TL culture & 2 & $33.33 \%$ \\
\hline \multirow{10}{*}{$\begin{array}{l}\text { Specific } \\
\text { pedagogy of } \\
\text { idioms }\end{array}$} & \multirow{10}{*}{$\begin{array}{l}\text { Strategies } \\
\text { of } \\
\text { translating } \\
\text { idioms }\end{array}$} & \multirow{3}{*}{$\begin{array}{l}\text { Instructors } \\
\text { teach } \\
\text { students } \\
\text { strategies to } \\
\text { translate } \\
\text { idioms } \\
\end{array}$} & 1 & 1 & Supportive & 3 & $50.00 \%$ \\
\hline & & & 2 & 2 & & & \\
\hline & & & & & Unsupportive & 3 & $50.00 \%$ \\
\hline & & \multirow{7}{*}{$\begin{array}{l}\text { Strategies } \\
\text { teachers } \\
\text { prefer in } \\
\text { translating } \\
\text { idioms }\end{array}$} & 1 & 2 & Idiom to idiom & 6 & $100.00 \%$ \\
\hline & & & 2 & 4 & Cultural approximation & 5 & $83.33 \%$ \\
\hline & & & 3 & 5 & Cultural substitution & 5 & $83.33 \%$ \\
\hline & & & 4 & 3 & Paraphrasing & 3 & $50.00 \%$ \\
\hline & & & 5 & 1 & Literal translation & 2 & $33.33 \%$ \\
\hline & & & 6 & 6 & Avoidance & 0 & $0.00 \%$ \\
\hline & & & 7 & 7 & Guessing & 0 & $0.00 \%$ \\
\hline
\end{tabular}

As for the category General pedagogy of idioms the following results were found:

A. As for the subcategory of idiom how do you teach idioms, the ideas were divided into two ranks: the ideas number 1 and 2 got a high rank while the ideas number 3, 4, and 5 got a low rank. The table shows that idioms are used through oral or written contexts, in normal language, or by asking students to translate and interpret them.

B. As for problematic idioms to students, the ideas were divided into three ranks: the ideas number 1, 2 and 3 got a high rank. The ideas number 4 and 5 got a moderate rank, and the idea number 6 got a low rank. The table indicates that the problematic expressions that are a source of difficulty were unfamiliar idioms; culture bound idioms, opaque idioms, idioms with different images, peculiar idioms, and lengthy idioms.

C. Concerning Prerequisite courses, the ideas were divided into two ranks: the ideas number 1, 2, and 3got moderate ranks while the ideas number 4 and 5 got a low rank. The Table indicates that teachers support the need for cultural specific courses.

D. As for Elaboration in explaining the differences between English and Arabic, the results were as follows:

1. As for The Instructors elaborated in explaining the differences between English and Arabic, the ideas were divided into 3 ranks: the idea number 1 got a high rank, the ideas number 2,3, and 4 got a moderate rank, and the idea number 5 got a low rank.The Table indicates that teachers elaborate if students lack cultural information, depending on students' level and motivation, and in case of difficult idioms.

2. As for The instructors give examples from both languages, the ideas number 1 and 2 got a high rank, the idea number 3 got a moderate rank, and the ideas number 4 and 5 got a low rank. The table indicates that teachers always 
give examples from both languages, when needed, to clarify the meaning, and when committing mistakes.

As for Feedback in translating idioms, the results were as follows:

1. As for Formative assessment, the ideas number 1 and 2 got a low rank. In Teachers advice to students, the idea number 1 got a moderate rank while the idea number 2 got a low rank. The Table shows that teachers assess students through quizzes and exams, class discussion.

2. Concerning teachers advice to students, they advise students consulting English dictionaries, and reading about the target language culture.

Concerning Specific pedagogy of idioms, the following results were found:

1. Concerning Instructors teach students strategies to translate idioms, the ideas number 1 and 2 got a moderate rank. The table shows that teachers teach students to translate idioms.

2. Concerning Strategies teachers prefer in translating idioms, the ideas number 1, 2, and 3 got a high rank. The idea number 4 got a moderate rank, and the ideas number 5, 6, and 7 got a low rank. The table indicates that teachers prefer translating with equivalent idiom, cultural approximation, cultural substitution, and literal translation.

4. Discussion

The discussion is presented according to the categories of analysis.

4.1 General Pedagogy of idioms

Looking back at table 3, it is noticed that a moderate percentage of translation instructors teach idioms through oral or written contexts by asking students to translate them, and by interpreting them. Furthermore, a very high percentage of translation instructors reported that they teach idioms incidentally when they come up with idioms. A moderate percentage of instructors reported that they teach idioms when they tackle cultural expressions. The instructors commented on this point in this manner:

\section{UJ Instructor: I try to ask students to give the translation into Arabic through the context in writing or speaking.}

UJ instructor: I wish to provide them in advance and ask them to look for its meaning either by using the internet or references and also you may wish to ask students to differentiate between their idiomatic and literal meaning.

$Y U$ instructor: We need first to take the idiom at the literal level and interprets its meaning. I make a strategy that is called interpretation, then I tried to find the functional equivalent if I can produce the same functionality. Take for example, the idiom it's raining cats and dogs if I translate it into Arabic, it is تمطر قططا وكلابا (tumtiru kitatan wa kilaaban) but this is not functional., so we try to give the ideational equivalentة̈اركابا bighazaarah), then I think of something else تمطر كافواه القرب( tumtiru ka'afwaahil qirabi), this is a functional equivalent.

As for the problematic idioms to students, a high percentage of the instructors indicated that they are the unfamiliar idioms, culture- bound idioms, and opaque idioms. Moderate percentage of them reported that idioms with different images, peculiar idioms, and lengthy idioms form a source of difficulty for students. It is clear from table 3 that there is an agreement between the students and their instructors concerning the types of idioms that form a source of difficulty for students. Translation instructors commented on this issue by saying:

YU instructor: Students normally face a problem in translating idiom which we call culture- bound idioms i.e idioms related to one culture i.e. idioms which are not known in the target culture.

YU instructor: Of course, opaque are opposed to transparent and means that the meaning is not clear. It is difficult to understand it first for the reader and it is even more difficult to translate to the target language.

UJ instructor: we have idioms in English in which the meaning of the individual words of an idiom cannot tell the meaning of the idiom. For example, take the idiom" bury the hatchet", if you take it literally you may come up with difficulty in knowing its meaning.

Brown (2001, p. 64) emphasizes the importance of culture in learning a second language and tackles the applications that a classroom teaching should include. He maintains that "cross-cultural understanding is important facet of learning a language". He also indicates that "Language and culture are intricately intertwined. Any time you learn a language, you will also learn something of the culture of the speakers of that language". He adds that "whenever you teach a language, you also teach a complex system of cultural customs, values, and ways of thinking, feeling, and acting".

Regarding the prerequisite courses, Table 3 indicated that a moderate percentage of instructors support the need for a cultural course in English and Arabic which is consistent with the students' points of view in this respect. Instructors commented on this issue by saying: 
YU instructor: Yes, I think this is important for students because these courses would certainly give them background knowledge on the two languages culture and help them to translate properly.

UJ instructor: I do not think there is a need to have a special course, but if there is a course offer it is fine.

As for the subcategory Elaboration in explaining the differencesbetween English and Arabic, the instructors said that they elaborate when students lack cultural information, depending on the students' level and motivation, and when the idioms are difficult. A high percentage of instructors reported that they give examples from both languages when needed. As for feedback in translating idioms, a moderate percentage of instructors advise students to consult English dictionaries of idioms and to read about the target language culture. These are samples of their comments on this issue:

UJ instructor: If students ask for more elaboration, I do it. Elaboration depends on students' motivation .It also depends on the level of students.

UJ instructor: You give attention to the different ones and less attention to the similar ones and the identical ones.

YU instructor: We elaborate in explaining the most difficult ones. It depends on your audience. If students are already aware of the idioms, then, there is no need to elaborate.

YU instructor: I make sure that they grasp the cultural component of that idiom. I asked them why did you translate it like this?

UJ instructor: Idioms are taught incidentally. They are not taught systematically. I check their production of idioms from time to time

\section{Specific Pedagogy of Idioms}

Table 3 shows that a moderate percentage of translation instructors teach students strategies to translate idioms. Also, it shows that a high percentage of the instructors preferred translating idioms using idiom to idiom strategy, cultural substitution, and cultural approximation.

The instructors indicate that teaching students how to translate idioms is not an easy task, especially when talking about opaque or peculiar idioms. Thus, some of them ask students to give the literal translation of the idiom if it conveys the meaning. If the literal translation does not work, they interpret the meaning of the idiom to students using paraphrasing. Then, they ask their students to give the equivalent in Arabic. These are samples of the instructors' comments on this issue:

YU Instructor: Sometimes the idiom could be transparent, then there is no harm in translating it literally. For example, in both Arabic and English we say walls have ears الحيطان لها أذان (alhitaan laha 'adaan).It is very literal but, very functional. If the literal translation is functional, it solves the problem.

UJ Instructor: I usually teach idioms through a context. The context could be either in writing or in speaking.

UJ Instructor: I wish to provide them in advance and ask them to look for their meaning either in the internet or using references. I may ask them to differentiate between the literal and the idiomatic meaning.

The suggested strategies for translating idioms by the instructors are almost consistent with the strategies used by their students. They were paraphrasing in the first rank, literal translation in the second rank, and cultural substitution in the third rank.

While instructors prefer that their students give an equivalent idiom in the target culture, it seems from the findings of the study that this is difficult for students to do because English and Arabic are two different languages with different cultures. In addition, most idioms are culture- bound expressions and peculiar to a given language and hence, what has a certain meaning in the source language does not necessarily have an equivalent in the target language. This makes the translation of idioms a tiring task for students in particular and for the translators in general because they have to be aware of the details of the two languages. Shunnaq (1993) writes:

Arabic and English are two languages which may be said to have sharply contrasting cultural backgrounds. Hence, a translator dealing with these languages should be both bilingual as well as bicultural ... in numerous cases it is extremely difficult not only to find an appropriate equivalence, but even to find an equivalence at all (p.8). 
Despite the fact that $74.4 \%$ of students were able to provide acceptable translations of the given idioms, few of them could be able to provide the functional equivalent, the matter which the researcher may attribute to the poor pragmatic competence of students. This is evidenced by the students' use of paraphrasing as a strategy to provide the ideational meaning followed by the use of formal equivalence. This in turn, indicates that students demonstrated difficulty in rendering English idioms into their Arabic cultural equivalents and this is supported by the translation instructors' views. Instructors comment on this issue by saying:

YU Instructor: Arabic and English as you know are remote languages not only linguistically, but also culturally, and hence the translation between the two languages is a tiring task.

YU Instructor: Each language has its own culture, proverbs, and idioms. What has a certain meaning in SL not necessarily has an equivalent meaning in the $T L$.

YUInstructor: Even the proficient translator would find them difficult to translate because you do not know exactly what does it mean. You have to think and guess, and this is not necessarily to be right all the time.

YU Instructor: Teaching translating idioms is a very difficult task, simply because the meaning of the idiom is not always transparent.

UJ Instructor: There are idiomatic expressions which are peculiar to a given language or a given culture.

UJ Instructor: Idioms that are relevant to idioms in Arabic would be quite easy. But, if we have two different cultures to express the same idiom. We may have two idioms in Arabic and English which have different images.

UJ Instructor: We have some idioms in English in which the meaning of the indivisual words of an idiom can't tell you the meaning of the idiom. For example, take the idiom "bury the hatchet"if we take the meaning of the words bury and hathet literally you may come up with difficulty.It means to put an end to hostility.

Farghal and Shunnaq (1999) tackle the issue of functional equivalence and stated three types of equivalence. They maintain that "Functional equivalence seeks to capture the function of the SL text independently of the image utilized by translating it into a TL expression that performs the same function" (p.7). They discuss the second and third types of equivalence and write:

There is ideational equivalence which aims to convey the communicative sense of the SL expression independently of function and form.... formal equivalence seeks to capture the form of the SL expression. Form here relates to the image employed in the SL expression ( p. 8).

Shunnaq (1993) elaborates:

Apart from conveying the message of the SL text into an equivalent message in the TL text, translation has another function, which is the transfer of the SL culture... culturally, the SL text and the TL text cannot always be equivalent. Certain terms may be used in the SL and the TL to refer to certain concepts but they may carry different connotations due to differences between the cultures of the two languages (p.152).

\section{Conclusion}

We might conclude from the analysis of the instructors' interviews that EFL instructors do teach the translation of idioms to EFL students. Yet, it is noticed that English idioms and their teaching do not receive much attention in the translation and English Language Programs. Furthermore, we can say that there is a need to teach a prerequisite cultural course to the translation students to introduce them to the target language culture since English and Arabic are two different languages linguistically and culturally. Also, it is noticed from the interviews' analysis that no much attention is paid to the idioms that form a source of difficulty for EFL students particularly opaque, semi- opaque and peculiar ones. Thus, students usually encounter difficulty in translating unfamiliar idioms into Arabic.

\subsection{Pedagogical Implications}

According to the findings of the current study, the following pedagogical implications might be considered:

1. EFL instructors should encourage their students to translate the meaning of idioms during reading, but direct teaching of idioms and explicit idioms learning (e.g. learning the meaning of an idiom from a dictionary) should go hand in hand with such encouragement.

2. EFL instructors should take into account the teaching of translating idioms to their students in hand with the teaching of translation strategies.

3. EFL translation instructors should raise their students' awareness of the strategies they use in translating in general, and in translating idioms in particular. 
4. EFL translation textbooks should present more idioms to EFL translation students with a focus on exposing students to the target language culture.

5. Students should study English/ Arabic specific course in idioms and culture as a prerequisite course to the translation courses.

6. Students should study a course or more to enhance their pragmatic competence in hand with the linguistic courses.

7. The teacher can help raise students' awareness of idioms' origins and improve their cultural knowledge through teacher instruction and many other procedures. A few weeks can be spent on these activities and learning a larger set of idioms or the teacher can, potentially, make a habit of integrating idioms into lessons and addresses them on occasion throughout the school year.

Acknowledgements

I am grateful to Prof Oqlah Smadi for proof reading this article.

\section{References}

Abu-Afeefa, R. (1987). Transfer in the acquisition of English idiomsby Jordanian University students. Unpublished M.A Thesis. Yarmouk University, Irbid, Jordan Retrieved on 15 ${ }^{\text {th }}$ Oct, 2012from http://search.proquest.com.ezlibrary.ju.edu.jo/docview /304773490?accountid=27719

Alrishan, A., \& Smadi, O. (2015). Difficulties EFL Jordanian University Students Encounter in Translating English Idioms into Arabic. Journal of Education and Practice, 6(10), 124-133.http://www.iiste.org/Journals/index.php/JEP/search/authors/view?

Bagheri, M., \& Fazel, I. (2010). Effects of etymological elaboration on EFL learners' comprehension and retention of idioms. Applied Linguisitcs, 14, 45-55. http://search.proquest.com.ezlibrary.ju.edu.jo/docview /304773490? accountid=27719

Baker, M. (1992). In other words: A coursebook on translation. London: Routledge.

Bataineh, R., \& Bataineh, R (2002). The Difficulties Jordanian Graduate Learners of English as a Second Language Face When Translating English Idioms into Arabic. RASK: internationalt tidsskrift for sprog og kommunikation16:33-83.http://search.proquest.com.ezlibrary.ju.edu.jo/docview /304773490?accountid=27719

Boers, F. (2008). Language Awareness: Understanding idioms. MEDMagazine, 49, 1- 4.

Boers, F., Eyckmans, J., \& Strenger, H. (2007). Presenting figurative idioms with a touch of etymology: More than mere mnemonic?.Language Teaching Research, 11(1), 43-62.http://search.proquest.com.ezlibrary.ju.edu.jo/docview /304773490? accountid=27719

Boers, F., Lindstromberg, S., Littlemore, J., Stengers,H., \& Eyckmans, J.(2008). Cognitive linguistic approaches to teaching vocabulary and Phraseology. New York: Mouton de Gruyter.

Boers, F., Piquer Píriz, A. M., Stengers, H., \& Eyckmans, J. (2009). Does pictorial education foster recollection of idioms? Language Teaching Research, 13(367), 367-382. http://search.proquest.com.ezlibrary.ju.edu.jo/docview /304773490?accountid=27719

Bromley, K. D. (1984). Teaching idioms. The Reading Teacher, 38(3), 272-276. http://search.proquest.com.ezlibrary.ju.edu.jo/docview /304773490?accountid=27719

Brown, H. (2001). Teaching by principles: An interactive approach to language pedagogy. Second Edition. White plains, Newyork:Pearson Education

Burke, D. (1998). Without slang and idioms, students are "In the Dark!”, ESL Magazine, 1(5), 20 - 23.

Chen, Y., \& Lai, H. (2013). Teaching English Idioms as Metaphors through Cognitive-Oriented Methods: A Case in an EFL Writing Class. English Language Teaching, 6(6), 13-20. http://search.proquest.com.ezlibrary.ju.edu.jo/docview /304773490?accountid=27719

Cooper, C. (1998). Teaching idioms. Foreign Language Annals, 31(2), 255-266. http://search.proquest.com.ezlibrary.ju.edu.jo/docview /304773490?accountid=27719

Cowie, A., \& Makkin, R. (1975). Oxford dictionary of phrasal verbs. Oxford: Oxford University Press.

Farghal, M., \& Talal, A. (1999). Translation with reference to English and Arabic: A practical guide. Irbid: Dar El-Hilal.

Fernando, C. (1996). Idioms and idiomaticity. Oxford: Oxford University Press.

Ghazala, H. ( 2004) . Essays in translation and stylistics. Beirut: Dr El- Ilm Lilmalayin. 
Hussein, R., Khanji, R., \& Makhzoumi, K. (2000). Idioms: Transfer or what? .Language and TranslationJournal,12,23-34,KingSaudUniversity.http://search.proquest.com.ezlibrary.ju.edu.jo/docview /304773490?accountid=27719

Lundblom E. G. E., \& Woods, J. J. (2012). Working in the classroom: Improving idiom comprehension through classwide peer tutoring, Communication Disorders Quarterly 2012, 33, 202-219. http://search.proquest.com.ezlibrary.ju.edu.jo/docview /304773490?accountid=27719

Newmark, P. (1981). Approaches to translation. Oxford: Pergamon Press.

Pimenova, Z. (2011). Idiom comprehension strategies used by English and Russian language learners in a think aloud study. Unpublished Doctoral Dissertation. Purdue University, West Lafayette, India.

Richards,J., \& Schmidt, R.(2002). Longman dictionary of language teaching and applied linguistics. London: Longman.

Smadi, O., \& Alrishan, A. (2015). Strategies Used by Jordanian EFL University Graduate Students in Translating Idioms into Arabic. Journal of Education and Practice, 6(6), 45-55. http://www.iiste.org/Journals/index.php/JEP/search/authors/view?

Shunnaq, A. (1993). Lexical incongruence in Arabic -English translation due to emotiveness in Arabic. turjman, 2(2), 37-63. http://search.proquest.com.ezlibrary.ju.edu.jo/docview /304773490?accountid=27719

Tran, H. (2012). An explorative study of idiom teaching for pre-service.Teahers. English Language Teaching, 5(12), 7686. http://search.proquest.com.ezlibrary.ju.edu.jo/docview /304773490?accountid=27719

Zhang, L. (2009). The effect of etymological elaboration on L2 idiom acquisition and retention in online environment. Unpublished M.A Thesis. Lowa State University, Lowa.

\section{(cc) BY}

This work is licensed under a Creative Commons Attribution 3.0 License. 